\title{
A PESQUISA EM TIPOGRAFIA NO DESIGN: Reflexões sobre as práticas de pesquisa em tipografia publicadas no P\&D Design entre 2008 e 2012
}

\section{TYPOGRAPHY RESEARCH IN DESIGN: Reflections on typography research published in P\&D Design between 2008 and 2012}

\author{
Claudia Bordin Rodrigues, MsC \\ UTFPR-Curitiba \\ cbsilva@utfpr.edu.br \\ Kando Fukushima, Msc \\ UTFPR- Curitiba \\ kando@utfpr.edu.br
}

\begin{abstract}
Resumo: $O$ presente artigo tem como finalidade identificar os aspectos culturais e metodológicos da pesquisa em Tipografia no Brasil, analisando as publicações de artigos dos Anais do P\&D Design entre 2008 e 2012. Tem como característica, o levantamento teórico das abordagens que consideram a pesquisa de campo em tipografia como elemento relevante na produção tipográfica brasileira, imaginando correlacionar as temáticas de interesse da comunidade científica no Brasil com as discussões de projeto e pesquisa em sala de aula e ampliando as discussões sobre a importância da pesquisa de campo, contextual e cultural, como elemento de construção do pensamento do designer pesquisador.
\end{abstract}

Palavras-chave: tipografia, P\&D Design, pesquisa em Design.

Abstract: The present paper aims to identify the cultural and methodological aspects of typography research in Brazil by analyzing papers presented on P\&D Design Proceedings between 2008 and 2012. The main characteristic is the theoretical investigation about approaches which consider fieldwork in typography research as a relevant element in Brazilian typographic production, aiming to correlate the interests of the scientific community in Brazil with discussions of design and research in the classroom, expanding discussions on the importance of fieldwork, contextual and cultural, as a fundamental aspect of the designer as researcher.

Palavras-chave: typography, P\&D Design, Design research. 


\section{INTRODUÇÃO}

O presente artigo apresenta uma parcela de um projeto de pesquisa em andamento, onde o principal objetivo é identificar metodologias de pesquisa e produção sobre tipografia no Brasil.

A ideia original partiu da demanda decorrente de uma atualização das matrizes curriculares dos cursos de graduação na universidade, onde os pesquisadores lecionam. Mesmo abordando vários tópicos importantes que envolvem a morfologia, legibilidade, aspectos históricos, principalmente da tipografia europeia e norte americana, terminologia básica e taxionomias existentes, as questões relacionadas aos aspectos culturais da tipografia e da produção brasileira em particular ainda são campos pouco explorados dada a relevância dessa temática.

Segundo Gruszynski (2007, p.123) pode se dizer que existe uma tendência contemporânea em relativizar o viés predominante da legibilidade como principal parâmetro de análise da tipografia, ainda que se reconheça seu papel fundamental.

Nesse sentido, as pesquisas realizadas em programas de pós-graduação e a produção científica apresentada em congressos e revistas acadêmicas no Brasil apresentam-se dentre as principais fontes para o acesso às discussões desses assuntos e consequentemente essenciais para a abordagem desses tópicos em disciplinas que abordam a tipografia em cursos de Design. Ressalta-se também como as abordagens que privilegiam um discurso sobre os aspectos culturais da tipografia, em sua pesquisa e produção, podem auxiliar e incentivar a pesquisa de campo, integrando essas práticas em projeto tipográfico.

\section{DESENVOLVIMENTO}

Para o escopo desse artigo, serão apresentadas as análises relacionadas a 15 artigos referentes às últimas 3 edições do P\&D Design (2008; 2010; 2012). Além disso, será apresentado sucintamente o referencial teórico bibliográfico utilizado. Em relação ao método de análise, numa primeira etapa, foram selecionados 44 artigos que tratavam do tema da tipografia nessas edições do P\&D, 11 artigos de 2008, 15 artigos de 2010 e 18 artigos de 2012. Posteriormente, foram elencados artigos de cada edição (em média, 5 artigos por edição) que estivessem mais restritamente ligados às questões culturais e metodológicas da investigação da tipografia no Brasil, seja pela pesquisa de campo e qualitativa, seja pelo viés histórico-cultural de peças e acervos. Quando os artigos apresentavam temas ou metodologias muito similares, ou ainda quando se tratavam de pesquisas que eram continuidade direta de outros artigos, foram apresentados apenas um deles. A análise considerou os objetivos da pesquisa, a metodologia utilizada e sua abordagem pelos autores, bem como a apresentação dos resultados obtidos.

\subsection{Referenciais teóricos}

A abordagem sobre os fatores culturais em tipografia são temas recorrentes na bibliografia da área. Bringhurst (2005) sugere que, respeitando os princípios da boa legibilidade, garantindo o papel central do texto em si em detrimento de soluções muito chamativas ou desarmoniosas, existe uma "tradição da tipografia", que deve ser honrada (p.31). Ainda que a ênfase em seu texto seja geralmente relacionada com as questões sintáticas da tipografia, é recorrente o uso de analogias que nos remetem aos valores culturais mais amplos. 
Ao discutir as classificações tipográficas, recorre novamente a um repertório amplo, criticando as taxionomias mais recorrentes e optando por relacionar a produção tipográfica com períodos históricos e derivativos dos respectivos movimentos artísticos:

"Há muitos sistemas de classificação de tipos em uso. Alguns deles usam termos fabricados, como "garalde" e "didone". Outros se valem de rótulos familiares mais vagos, tais como "old style" ou "estilo antigo", "moderno" e "transicional". Todos esses sistemas funcionam até certo ponto e todos deixam muito a desejar. Ao fim e ao cabo, não fazem nem boa ciência nem boa história. (...) No entanto, as letras não são apenas objetos da ciência, pois também pertencem ao âmbito da arte e participam de sua história. Elas têm mudado com o tempo do mesmo modo que a música, a pintura e a arquitetura (BRINGHURST, 2005, p. 135)."

Levando em consideração esta perspectiva, e não necessariamente as opiniões e julgamentos sobre os usos da tipografia que o autor demonstra em seu livro, podemos pensar sobre essas questões na produção tipográfica brasileira, assim como nas relações possíveis com a produção visual atual.

O uso de tipos clássicos ou mesmo àqueles recentes de derivação morfológica mais tradicional, de fato representam uma perspectiva fundamental para o estudo e uso da tipografia. No entanto, diante de um número cada vez maior de suportes e variedade de usos, resta-nos pesquisar outras possibilidades para essas questões.

Priscila Farias (1998) explora a relação da produção tipográfica com questões artísticas e as possibilidades abertas pelas tecnologias digitais. Ao apresentar as influências históricas e examinar exemplos de tipografias consideradas "contemporâneas" conclui que uma interpretação restrita do uso da tipografia como "instanciador gráfico da linguagem verbal" (p.93) não é possível. Sendo assim, as qualidades morfológicas dos caracteres não podem ser avaliadas supondo apenas sua eficiência em termos de legibilidade, por exemplo.

Um exemplo histórico citado pela autora que ilustra bem as questões relacionadas ao design tipográfico, por um viés dito objetivo mas que se confunde com uma perspectiva cultural e histórica bem específica, é o que diz respeito às variações do alfabeto latino em relação os seus conceitos visuais diferentes para a mesma letra em seu desenho em caixa baixa e caixa alta e as ideias de "universalidade" do modernismo:

“(...) tipógrafos modernistas como Herbert Bayer e Jan Tschichold propuseram alfabetos que dispensariam o uso de mais de um conceito de letra para cada caractere (...) é preciso notar que a 'volta à essência pura e verdadeira' das letras, almejada pelos primeiros tipógrafos modernistas, colocava-se em franca oposição, tanto à profusão de tipos ornamentais usados em cartazes e letreiros, quanto à revalorização de formas tipográficas 'clássicas' (FARIAS, 1998, p.93-94)."

Gruszynski (2007), define a noção tradicional do design tipográfico como mediadora neutra entre a palavra do autor e o leitor (p.115). Indicando uma das possibilidades de extrapolar essa abordagem, cita o conceito de 'cultura gráfica', que considera os objetos escritos e as práticas determinadas historicamente.

A edição do texto, seus suportes e materialidade, constituem a relação histórica entre leitor e texto (p.118), envolvem aspectos técnicos específicos que não são 'naturais', mas sim datados e transitórios. Por esse viés, além das formas de escrita, considera-se a variedade de usos e podemos interpretar as abordagens existentes, sejam elas culturais ou mais técnicas, num contexto crítico mais amplo. 
$\mathrm{Na}$ introdução de seu livro, Finizola (2010) identifica através de projetos de fontes digitais brasileiras e também de eventos nacionais sobre tipografia, momentos onde ficam evidentes nas novas produções de designers a abordagem de uma referência às culturas locais (p.15). Seu livro apresenta uma contribuição importante ao tema, sistematizando conceitos e métodos de investigação, particularmente da produção da tipografia vernacular e especialmente a contextualizada na cidade de Recife.

\subsection{P\&D Design 2008}

Dos artigos selecionados dessa edição, o mapeamento da paisagem urbana tipográfica foi tema de Farias et al (2008), cujo objetivo dos pesquisadores foi o de fazer um levantamento documental das epígrafes arquitetônicas da cidade de São Paulo, tendo como base os mapas regionais do zoneamento em diversos períodos históricos.

Os pesquisadores usaram de técnicas de pesquisa de campo, tais como observação in loco, mapeamento e uso de fotografias, como suporte para a comparação de padrões arquitetônicos encontrado nessas peças, que segundo Baines \& Dixon (2003) reflete o orgulho de certos construtores pelo seu trabalho. As análises das epígrafes paulistanas, segundo os autores, revelaram um acervo de referência sobre a produção de engenheiros, arquitetos, construtores e outras empresas responsáveis pela obra, sendo que alguns até mesmo eram nomes pouco lembrados na história da arquitetura da cidade.

É evidente a valorização dos praticantes (construtores e arquitetos), considerando a intenção declarada de "documentar para a reflexão" (p.12), possibilitando recursos de análise da escrita e por vezes, o resgate histórico desses sujeitos.

Os elementos de análise expressos pelos autores do artigo reforçam a contribuição dos designers para a documentação da cidade, isto é, uma antropologia tipográfica que permita um diálogo entre a valorização da produção dos praticantes e o uso das técnicas de pesquisa de campo e mapeamento, explorando o potencial do designer-etnógrafo (PLOWMAN, 2003).

Já as autoras Aragão e Farias (2008) apresentam um levantamento bibliográfico sobre a história dos tipos em metal com o objetivo de fazer um levantamento da tipografia encontrada em manuais e catálogos da Editora UFPE para catalogação, registro e posterior uso em projetos experimentais. Como projeto de extensão, foram analisadas as caixas tipográficas da Editora, listados e contados os caracteres (typefaces), comparação anatômica, agrupamentos e investigação exploratória sistemática dos tipos encontrados e suas fundidoras.

Neste caso, a análise sistemática da anatomia e sua comparação e catalogação são aspectos de relevância para o estudo morfológico e anatômico, propondo a vivência de contato com os tipos móveis e promovendo exploração dessas matérias primas em projeto.

Novaes et al (2008) também utilizam da tipografia urbana como matéria prima de estudo, considerando dois instrumentos de pesquisa (mapa de rotas e Tomos Epigráficos) como ferramenta de análise para mapear os elementos tipográficos de uma área delimitada do centro histórico da cidade de São Paulo. Nesta pesquisa, os 
autores apresentam com detalhe o processo de definição das rotas dentro de um zoneamento urbano, identificando os elementos arquitetônicos da pesquisa, ferramenta que segundo eles, foi base para coordenação das atividades do grupo de pesquisadores. No Tomos Epigráfico, uma tabela apresenta os dados de acervo com elementos de catalogação, permitindo a inserção das imagens dos edifícios e das peças gráficas catalogadas. $O$ uso da planilha, segundo os autores, mostrou-se eficiente, dando suporte a pesquisa de campo dentro das rotas e facilitando o registro e catalogação.

Neste artigo, a sistematização de um processo de pesquisa de campo em tipografia é um tema que permite-se nos refletir sobre a necessidade de criação de modelos, apoiados em ferramentas gerais do levantamento de dados estatísticos ou coleções.

A análise de uma coleção de peças gráfica, dentro dos acervos de catálogos e impressos também pode ser matéria prima de suporte cultural relevante para a documentação tipográfica, no que indica o trabalho de Migliari e Farias (2008). Elas apresentaram os dados parciais de uma documentação sobre "Tipografia pós moderna no Brasil", utilizando como base os catálogos das Bienais de Design Gráfico promovidas pela ADG (Associação dos Designers Gráficos).

Para tanto, as autoras digitalizaram os catálogos e iniciaram um processo de identificação da tipográfia pós-moderna, a partir das fundamentações de Poynor e Booth-Clibborn, na obra Typography now: the next wave (1991) e nas revistas da década de 90, tais como Fuse, Emigre e Eye Magazine. Já os autores Steven Heller e Louise Fili, em seu livro Typology: type design from the Victorian era to the digital age (1999), foram utilizados como suporte as definições categóricas de classificação, tais como subjetividade, experimentação, legibilidade, presença de ornamentos ou uso de fontes não convencionais, dentre outras categorias (Migliari e Farias, 2008).

Ao final da pesquisa, as autoras mostram o instrumento de análise criado para a categorização frente a listagem gerada, que permite apresentar a peça (fotografia) e classificá-la de modo abrangente frente a relevância dos critérios, ressaltando a finalidade da proposta:

“[...] a análise do conjunto de tabelas preenchidas fornecerá conclusões tanto de natureza qualitativa -teor de pós-modernidade- quanto conclusões quantitativas -espectro de influência pós-moderna no âmbito da produção nacional em design gráfico (p.5)."

Dessa forma, reflete-se sobre a produção brasileira e sua legitimidade frente as categorias do pós moderno na Tipografia, considerando um instrumento de análise valoroso para a continuidade de projetos de mesma temática. Migliari e Farias (2008) reforçam a continuidade da pesquisa e a necessidade de complementação dos dados, visto posteriormente na publicação de novo artigo em 2012, neste mesmo evento.

\subsection{P\&D Design 2010}

Finizola e Coutinho (2010) apresentam um processo de construção de padrões tipográficos nos letreiramentos populares, considerando os aspectos de autoria, representação da linguagem e atributos formais. As autoras partem do pressuposto que parte dos letreiramento popular advém de influências genuinamente vernaculares, históricas e da tradição, como elemento cultural da memória de uma cidade (neste caso, a cidade de Recife) e que a documentação da informalidade dessas peças gráficas é de relevância para o desenvolvimento de "fontes populares digitais" 
no futuro (p.3).

Para a construção de um método de registro e catalogação próprio e maleável, as autoras utilizam um modelo inicial de análise contido em Valadares (2007), inspirado no sistema de catalogação do Museu Nacional de Belas Artes, SIMBA/Donato, para o registro das peças gráficas e suas características. A seguir, apoiam-se nos atributos propostos por Dixon (2008) para a análise dos aspectos formais, tais como a Construção, Proporção, Modulação, Peso, Serifas, e também em Aragão et AL (2008) na análise dos aspectos extrínsecos aos letreiros populares, tais como o layout do artefato.

Quanto aos aspectos de autoria, Finizola e Coutinho (2010) distinguem três padrões perceptíveis na produção dos letreiramentos, como aqueles dito nãoespecialista (manuscritos populares), especialista (feito por profissionais) e autoral (feitos como expressão subjetiva). Já em relação a forma de representação da linguagem gráfica verbal, foram identificadas as bases caligráficas, tipográficas e de desenho. Por último, os atributos formais referem-se a semelhança de construção formal, descritas como amadoras, quadradas, toscanas, cursivas, gordas, serifadas, expressivas, fantasia e caligráficas.

Na construção textual das autoras, é evidente a valorização da originalidade e processo criativo do letreirista amador frente aos processos técnicos e digitais, considerando que as ferramentas e tecnologias influenciam diretamente no resultado das produções, permeando com maior ou menor intensidade os centros urbanos e a periferia ou comunidade, como citam:

\footnotetext{
"Nas peças desenvolvidas para pequenos estabelecimentos ou comerciantes informais, há uma maior liberdade de criação e maior originalidade no estilo tipográfico desenvolvido pelos letristas, que podem tomar partido de um estilo pessoal mais autoral, sem seguir regras préestabelecidas (FINIZOLA e COUTINHO, 2010, p.11)."
}

Freire e Cavalcanti (2010) apresentam uma metodologia para a produção de fontes digitais considerando como suporte as características dos letreiramentos encontrados na coleção de rótulos "Imagens Comerciais de Pernambuco", que tem como restrição o número de caracteres visíveis nas peças gráficas, muitas vezes nomes simples compostos de 5 a 8 caracteres. As autoras apoiam-se na árvore de derivação das caixas altas, de Buggy (2007) adaptado de Adams (1989), como meio de criar um conjunto maior de caracteres que mantenha unidade estilística e caligráfica.

Neste processo, as autoras utilizaram-se dos recursos digitais para redesenhar as formas geométricas, hastes e serifas, ora agrupando rótulos semelhantes, ora estabelecendo as características formais-chave para a replicação em um conjunto maior. Como resultado, apresentam os conjuntos de caracteres Pitiguary e São João, ambos em fase de desenvolvimento pelas autoras. Reforça-se nesse artigo o uso reflexivo do suporte gráfico aliado a fundamentação teórica sobre anatomia, auxiliando inclusive na categorização histórica das peças analisadas, como se observa:

"Quando escolhido o critério originalidade, foi preciso, inicialmente, buscar referências a fim de obter mais informações sobre as formas dos caracteres. Esse foi o caso da fonte gerada a partir da palavra São João do rótulo Hidromel. Através da relação entre a espessura das hastes das letras e de suas formas orgânicas, identificou-se que o letreiramento possuía características do movimento Art Nouveau (FREIRE e CAVALCANTI, 2010, p.3)." 
Ferreira (2010) apresenta e discute alguns letreiramentos no cinema nacional dos anos 60, apontando a visualidade do design gráfico moderno nesses trabalhos.

No artigo, os letreiramentos de filmes se referem principalmente aos créditos iniciais (title design), sendo que a principal referência internacional da época era Saul Bass, designer dos créditos de "O homem do braço de ouro" (1955) de Otto Preminger. Por este viés, o autor identifica em trabalhos de letreiramento de diversos filmes brasileiros dos anos 60, a influência de uma linguagem associado ao design moderno, como o uso da tipografia sem ornamentos, equilíbrio assimétrico dentre outras características formais.

As soluções visuais desses filmes, muitas vezes contendo temáticas regionais, demonstram as articulações formais do design gráfico em outros suportes visuais, em meios de expressão cultural bastante influentes na sociedade. Destaca dentre os designers de letreiros brasileiros, Roberto Miller e a artista Lygia Pape, cuja produção era bastante ligada ao cinema, além de citar nomes como Ziraldo, Glauco Rodrigues e Valdi Ercolani, cuja produção nesse meio era esporádica.

Dentre os filmes mais conhecidos do período, descreve e aponta as características formais de filmes como "Vidas secas" e "Deus e o Diabo na Terra do Sol", ambos com letreiramentos realizados por Pape.

Como exemplo da argumentação do autor quanto aos aspectos culturais, a produção fílmica e sua relação com a soluções de design utilizadas no letreiramentos podemos citar:

"A sobriedade, a economia e o despojamento dos letreiros de Pape se adequam à proposta do

"Cinema Novo": é direto, verdadeiro e até mesmo original, sem emulações ao padrão visual norte-americano. Também é novo, fresco, arejado, liberto dos ícones e grafismos decorativos. Ao mesmo tempo também é adequado à realidade econômica da produção nacional da época, já que era prático, barato e fácil de ser produzido. (FERREIRA, 2010, s.p.)"

Aragão (2010) realiza uma pesquisa histórica sobre os tipos móveis de metal no Brasil através da análise de oito catálogos de duas das principais fundidoras de tipos atuantes no Brasil, a Funtimod e a Manig.

Com a análise dos catálogos (06 da Funtimod e 02 da Manig), a autora pode verificar quais as famílias tipográficas estavam disponíveis, quais eram importadas ou fundidas localmente e como esses produtos eram apresentados. Mesmo não sendo possível identificar a data precisa desses materiais, pode se dizer que abrange catálogos datados entre os anos 40 até os anos 80 . A pesquisadora também mostra algumas das características dessas empresas e sua relevância no território nacional, indicando por exemplo onde essas empresas possuíam filiais.

Dessa forma, Aragão (2010) contribui efetivamente com as pesquisas sobre o design gráfico brasileiro, mostrando uma parcela importante do que estava disponível para os projetos que utilizavam a composição manual no século XX.

\subsection{P\&D Design 2012}

O artigo de Noronha, Santos e Portela (2012) deixa bem clara a intenção de estabelecer a tipografia como um dado cultural importante numa comunidade específica. Para este fim, propõe a utilização da etnografia como método de investigação, ou seja, estuda a tipografia de forma articulada com abordagens da Antropologia. A pesquisa está inserida no corpo de um projeto de mapeamento da produção iconográfica cultural, chamado Iconografias do Maranhão e a pesquisa de 
campo ocorreu junto aos carpinteiros navais da área Itaqui-Bacanga - São Luís, MA.

Com a finalidade de delimitar um pouco melhor os conceitos e qualidades envolvidas nessa abordagem, citamos a definição de etnografia, segundo os autores:

"[...]a etnografia caracterizada por inúmeras etapas que perpassam a identificação, observação, descrição, classificação e interpretação dos significados simbólicos dos fazeres, dos saberes e das histórias de determinado grupo ou cultura e, ainda, as formas tangíveis destes significados - seus produtos, seus objetos e suas imagens, ou seja, a sua cultura material (NORONHA; SANTOS; PORTELA, 2012, s.p.)."

No que diz respeito à tipografia propriamente dita, classifica a produção como "tipografia popular", utilizando a definição de Martins (2007). Além dos aspectos formais das letras, a pesquisa envolve a entrevista com as pessoas que realizaram os trabalhos, as motivações para as soluções visuais e os significados atribuídos.

O trabalho de Guimarães e Lessa (2012), investiga os pintores de letras da cidade do Rio de Janeiro, utilizando as entrevistas e análise dos trabalhos como meio de acesso aos repertórios específico utilizados na produção. No entanto, além dessas informações, os autores usam como referência de análise e comparação as técnicas de pintura de letras apresentadas em manuais norte-americanos dos anos de 1890 até 1920. Diante do fato de que a maioria dos pintores afirmavam ser autodidatas, é interessante perceber a recorrência de técnicas e soluções visuais entre eles, além de evidenciar algumas de suas diferenças. Neste trabalho, o conhecimento tácito dos pintores é discutido em conjunto com o material didático disponível num período específico, trazendo uma reflexão importante para a produção de design gráfico e tipográfico em particular.

Através desse método de pesquisa, questionam algumas abordagens recorrentes ao modo de produção tipográfica:

"A consideração desta mecânica e a análise dos artefatos documentados na pesquisa nos leva a duas constatações. A primeira vem contestar a percepção de que os pintores de letras tendem a processos de trabalho não sistematizados. Mesmo elementares, os procedimentos e referências caracterizam uma estrutura geral da atividade. A segunda põe por terra a crença ingênua de que os pintores populares de letras são essencialmente criativos: a aplicação "burocrática” de modelos mostra o oposto (GUIMARÃES; LESSA, 2012, s.p.). “

Dando continuidade a um artigo apresentado em 2008, Migliari (2012) apresenta um panorama da produção tipográfica brasileira "pós-moderna", baseado nos catálogos das Bienais da ADG (Associação dos Designers Gráficos) entre 1992 e 2009. Dentre os objetivos, destaca-se a proposta de delinear as características visuais e conceituais da produção tipográfica brasileira.

O método de investigação se baseia na análise de catálogos, portanto utiliza a fonte bibliográfica como principal meio de acesso à produção, no entanto, a fim de identificar e aprofundar os aspectos qualitativos, também foram realizadas entrevistas. As entrevistas foram realizadas após uma primeira análise dos trabalhos, onde se identificou aqueles que utilizam mais as características pós-modernas segundo as categorias da autora.

Ao optar por analisar os trabalhos selecionados pelas Bienais da associação de classe, a relevância da amostragem é estabelecida de forma bem clara, o que poderia ser uma grande dificuldade nesse contexto, principalmente no que diz respeito aos critérios de seleção do trabalho.

Apesar dos desafios implícitos nas definições conceituais envolvidas, 
particularmente no que se refere a uma tipografia pós-moderna, a autora estabelece uma série de categorias levantadas por diversos autores da área e as classifica como sendo aquelas que tratam de aspectos conceituais (estratégias) ou visuais, privilegiando os visuais na análise.

Embora não seja o intuito deste artigo descrevê-las, cita-se as características visuais elencadas para uma melhor compreensão da proposta: Presença de ornamentos; Uso de fontes experimentais; Uso de referências vernaculares; Tipografia eclética; Múltiplas camadas de texto - layering; Distorção visual do texto; Ruptura com caminhos convencionais de leitura; Tipografia deteriorada; Formas flutuantes; Colagens; Elementos tecnológicos - techno.

Assim, utilizando as categorias visuais, identifica quais delas estão presentes nos trabalhos apresentados. Posteriormente, foi possível utilizar essas informações nas entrevistas, verificando os contextos e discutindo o referencial teórico.

Lima (2012) investiga a questão da tipografia no Brasil por um viés histórico. Sua pesquisa aborda o fundidor de tipos Luis Muratet, durante o período de 1859 e 1865. Este período está relacionado à época em que o português trabalhou como mestre instrutor de fundição de tipos no Instituto dos Menores Artesãos da Casa de Correção e a constituição de sua oficina de fundição de tipos, que posteriormente foi transferido para a Imprensa Oficial.

A fonte utilizada para a pesquisa foram relatórios ministeriais, os Relatórios Anuais dos Ministros da Fazenda e da Justiça do Segundo Reinado (1859-1866) e particularmente uma do Diretor da Imprensa Oficial, na época sob a jurisdição do Ministério da Fazenda. Assim foi possível verificar a listagem de itens, contratos de serviços e valores relacionados às transações entre Muratet e o governo.

Finizola e Coutinho (2012) descrevem a metodologia de trabalho de um grupo de estudos de alunos de Graduação em Design da Universidade Federal de Pernambuco, 'Memória Gráfica Pernambucana: manifestações vernaculares', que teve duração de quatro meses. Este artigo aborda objetivamente uma metodologia de trabalho com alunos em disciplinas de tipografia e correlatas.

O conceito de tipografia vernacular é recorrente em outros artigos apresentados, no entanto, destaca-se a definição das autoras para este tipo de manifestação visual, por possuir uma articulação profunda com um dos objetivos do presente artigo:

"A tipografia vernacular particularmente nos chama atenção por registrar na paisagem urbana as vozes reprimidas de uma periferia que sutilmente avança nos espaços públicos do centro, revelando hábitos e costumes de um povo. (...) (FINIZOLA; COUTINHO, 2012, s.p.)."

O grupo de estudos investigou as paisagens visuais das ruas e bairros da Região Metropolitana do Recife. Refere-se assim aos artefatos informais da comunicação, nos espaços públicos geralmente produzidos por técnicas manuais ou artesanais.

A metodologia descrita recorre a um trabalho anterior das autoras (COUTINHO; FINIZOLA, 2010), no que diz respeito ao registro e catalogação dos artefatos, já citado anteriormente. Além da catalogação, foram considerados aspectos da confecção desses materiais, tais como métodos de produção e ferramentas utilizadas, referências no processo criativo, discussões em seminários. Uma particularidade deste grupo de estudos foi incluir o desenvolvimento de um projeto tipográfico com os alunos, exemplificando a prática da pesquisa científica aplicada ao projeto gráfico. 


\subsection{Discussões}

Considerando o período de tempo estudado (de 2008 a 2012) foi possível observar que alguns trabalhos de pesquisa tiveram sua continuidade apresentada no mesmo evento, o que parece revelar uma trajetória de acompanhamento da comunidade científica do $P \& D$ às temáticas que envolvem cultura, sociedade $e$ historicidade na pesquisa em Tipografia.

Embora a amostra seja reduzida em termos gerais, sua representatividade em relação a diversidade de interesse e abordagens parece permitir algumas considerações sobre a comunidade tipográfica dentro do evento, que manteve-se estável durante o período, mas com aprimoramento de técnicas e reapresentação de artigos. No Quadro 1 (parcial) apresenta-se parte das análises sobre a metodologia, objetivos e resultados:

\section{Quadro 1 - Listagem dos artigos analisados - quadro parcial das análises}

Fonte: Elaborado pelos autores.

\begin{tabular}{|l|l|l|l|}
\hline Artigo & $\begin{array}{l}\text { Abord. Metodológica e } \\
\text { ferramentas de pesquisa }\end{array}$ & Objetivos da pesquisa & Resultados obtidos \\
\hline $\begin{array}{l}\text { Epigrafia arquitetônica } \\
\text { paulistana - indícios da } \\
\text { história da cidade } \\
\text { inscritos no espaço } \\
\text { público }\end{array}$ & $\begin{array}{l}\text { Mapeamento de } \\
\text { zoneamento urbano uso de } \\
\text { fotografia, comparação de } \\
\text { padrões arquitetônicos. }\end{array}$ & $\begin{array}{l}\text { Registro, análise e } \\
\text { documentação das } \\
\text { Características das } \\
\text { epígrafes arquitetônicas } \\
\text { do centro histórico da } \\
\text { cidade de São Paulo. }\end{array}$ & $\begin{array}{l}\text { Criação de um banco de } \\
\text { dados com referencias das } \\
\text { obras de diferentes } \\
\text { da cidadores em períodos } \\
\text { históricos distintos. }\end{array}$ \\
\hline $\begin{array}{l}\text { Metodologia para } \\
\text { Análise da Tipografia } \\
\text { Pós-Moderna } \\
\text { nas Bienais de Design } \\
\text { Gráfico da ADG (2008). }\end{array}$ & $\begin{array}{l}\text { Pesquisa bibliográfica sobre } \\
\text { categorias e características } \\
\text { da tipografia e design pós- }\end{array}$ & $\begin{array}{l}\text { Análise da produção } \\
\text { brasileira citada nos } \\
\text { catálogos da ADG entre } \\
\text { 1992 a 2009. }\end{array}$ & $\begin{array}{l}\text { Criação de ferramenta de } \\
\text { análise tipográfico com } \\
\text { vasto conjunto de } \\
\text { categorias. }\end{array}$ \\
\hline $\begin{array}{l}\text { A inserção do design } \\
\text { moderno nos letreiros } \\
\text { dos filmes brasileiros } \\
\text { nos anos 1960. }\end{array}$ & $\begin{array}{l}\text { Pesquisa bibliográfica } \\
\text { histórica sobre filmes e } \\
\text { produção de letreiros no } \\
\text { Brasil }\end{array}$ & $\begin{array}{l}\text { Análise das peças } \\
\text { gráficas do cinema } \\
\text { brasileiro. }\end{array}$ & $\begin{array}{l}\text { Análise e fundamentação } \\
\text { de discussão. }\end{array}$ \\
\hline $\begin{array}{l}\text { Apontamentos sobre } \\
\text { design tipográfico a } \\
\text { partir da coleção } \\
\text { Imagens Comerciais de } \\
\text { Pernambuco. }\end{array}$ & $\begin{array}{l}\text { Análise de peças gráficas, } \\
\text { comparação histórica e } \\
\text { produção/criação } \\
\text { tipográfica. }\end{array}$ & $\begin{array}{l}\text { Análise e escolha de } \\
\text { tipografia em rótulos e } \\
\text { produção de conjunto } \\
\text { tipográfico. }\end{array}$ & $\begin{array}{l}\text { Documentação dos rótulos } \\
\text { e produção de conjunto de } \\
\text { caracteres tipográficos. }\end{array}$ \\
\hline
\end{tabular}

Afirma-se também que, em vários artigos apresentados nesta revisão, o resultado obtido na proposta foi gerador também de um modelo, fundamentação ou conjunto de ferramentas de análise, o que pode gerar dois pontos importantes de discussão: o primeiro reforça a necessidade de metodologias de pesquisa próprias em tipografia, considerando um universo diverso de interesses e contextos, geralmente advindos da academia. O outro, respondendo diretamente ao primeiro, refere-se a motivação e produtividade dos autores que, não encontrando ferramentas próprias para os seus contextos de análise, criam, testam e validam seus próprios instrumentos de pesquisa, gerando material valoroso de publicação na comunidade científica. 


\section{CONCLUSÃO}

O presente artigo por apresentar apenas os resultados iniciais da pesquisa, possui limitações no que diz respeito às reflexões críticas mais profundas sobre o assunto. No entanto, a contextualização das pesquisas e a necessidade de discussão metodológica proposta por parte dos autores analisados nos artigos do P\&D, evidencia e aponta uma contribuição relevante das pesquisas em tipografia no Brasil como fonte de produção de dados para o modelo de ensino e aprendizagem no Design.

Sob este ponto de vista, foi possível categorizar alguns temas e métodos recorrentes para a análise de aspectos culturais da tipografia, assim como sugestões de métodos para a abordagens desses temas aplicados ao ensino de tipografia no nível de graduação. É importante ressaltar a importância que os aspectos históricos e culturais trazidos pela comunidade científica reforçam um compromisso de documentação e registro da tipografia no Brasil, demonstrando aos jovens principiantes como os homens e mulheres criadores de tipos atingiram os objetivos de leitura e expressão da estética de seu tempo.

Como continuidade desse projeto, pretende-se ampliar a discussão sobre as produções de metodologia de pesquisa em tipografia, articulando categorias de análise para o entendimento dos fatores culturais. Outra abordagem refere-se a extensão da análise a outros eventos científicos de Design no Brasil, localizando os discursos das pesquisas tipográficas nacionais e de seus praticantes.

\section{REFERÊNCIAS}

ARAGÃO, I. Um breve panorama dos catálogos de tipos das fundidoras Funtimod e Manig. In: Congresso Brasileiro de Pesquisa e Desenvolvimento em Design, 2010, São Paulo. Anais do $9^{\circ}$ Congresso Brasileiro de Pesquisa e Desenvolvimento em Design. São Paulo: 2010.

ARAGÃO, I. FARIAS, A.M. Tipos móveis de metal: de Gutenberg até os dias atuais. In: Anais do 8o Congresso Brasileiro de Pesquisa e Desenvolvimento em Design - P\&D Design 2008. São Paulo: Centro Universitário SENAC, 2008.

BRINGHURST, R. Elementos do estilo tipográfico. São Paulo: Cosac Naify, 2005.

FARIAS, P. Tipografia digital. Rio de Janeiro: 2AB, 1998.

FARIAS, P.L et. al. Epigrafia arquitetônica paulistana - indícios da história da cidade inscritos no espaço público. In: Congresso Brasileiro de Pesquisa e Desenvolvimento em Design, 2008, São Paulo. Anais do 8o Congresso Brasileiro de Pesquisa $e$ Desenvolvimento em Design - P\&D Design 2008. São Paulo: Centro Universitário SENAC, 2008.

FERREIRA, F. A. A inserção do design moderno nos letreiros dos filmes brasileiros nos anos 1960. In: Congresso Brasileiro de Pesquisa e Desenvolvimento em Design, 2010, São Paulo. Anais do $9^{\circ}$ Congresso Brasileiro de Pesquisa e Desenvolvimento em Design. São Paulo: 2010.

FINIZOLA, F. Tipografia vernacular urbana. São Paulo: Blucher, 2010.

FREIRE, A. CAVALCANTI, A. Apontamentos sobre design tipográfico a partir da coleção Imagens Comerciais de Pernambuco. In: Congresso Brasileiro de Pesquisa $e$ Desenvolvimento em Design, 2010, São Paulo. Anais do $9^{\circ}$ Congresso Brasileiro de 
Pesquisa e Desenvolvimento em Design. São Paulo: 2010.

FINIZOLA, F. COUTINHO, S. Uma classificação tipográfica para os Letreiramentos Populares. In: Congresso Brasileiro de Pesquisa e Desenvolvimento em Design, 2010, São Paulo. Anais do $9^{\circ}$ Congresso Brasileiro de Pesquisa e Desenvolvimento em Design. São Paulo: 2010.

FINIZOLA, F.; COUTINHO, S. Investigando as paisagens tipográficas urbanas. In: Congresso Brasileiro de Pesquisa e Desenvolvimento em Design, 2012, São Luís. Anais do $10^{\circ}$ Congresso Brasileiro de Pesquisa e Desenvolvimento em Design. São Luís: 2012.

GUIMARÃES, V. F. da S.; LESSA, W. D. Pintores de letras ativos na cidade do Rio de Janeiro: conhecimento tácito e antigos manuais de letreiramento. In: Congresso Brasileiro de Pesquisa e Desenvolvimento em Design, 2012, São Luís. Anais do $10^{\circ}$ Congresso Brasileiro de Pesquisa e Desenvolvimento em Design. São Luís: 2012.

GRUSZYNSKI, A. C. A imagem da palavra. Rio de Janeiro: Novas Ideias, 2007.

LIMA, E. L. C. O fundidor de tipos Luis Muratet e sua atuação no Rio de Janeiro (18591865). In: Congresso Brasileiro de Pesquisa e Desenvolvimento em Design, 2012, São Luís. Anais do $10^{\circ}$ Congresso Brasileiro de Pesquisa e Desenvolvimento em Design. São Luís: 2012.

MARTINS, B. G. Tipografia popular: Potências do ilegível na experiência do cotidiano. São Paulo: Annablume, 2007.

MIGLIARI, M. Um Olhar para a Tipografia Pós-moderna Brasileira: Metodologia. In: Congresso Brasileiro de Pesquisa e Desenvolvimento em Design, 2012, São Luís. Anais do $10^{\circ}$ Congresso Brasileiro de Pesquisa e Desenvolvimento em Design. São Luís: 2012. MIGLIARI, M. FARIAS, P. Metodologia para Análise da Tipografia Pós-Moderna nas Bienais de Design Gráfico da ADG. In: Congresso Brasileiro de Pesquisa e Desenvolvimento em Design, 2008, São Paulo. Anais do 8o Congresso Brasileiro de Pesquisa e Desenvolvimento em Design - P\&D Design 2008. São Paulo: Centro Universitário SENAC, 2008.

NORONHA, R.; SANTOS, M. A.; PORTELA, R. L. Embarcações e Manguezais: tipografia e etnometodologia. In: Congresso Brasileiro de Pesquisa e Desenvolvimento em Design, 2012, São Luís. Anais do $10^{\circ}$ Congresso Brasileiro de Pesquisa e Desenvolvimento em Design. São Luís: 2012.

NOVAES, F.; INDICATTI, F.; GOUVEIA, A.; FARIAS, P. Tipografia Urbana - mapeamento e organização de acervo. In: Anais do 8o Congresso Brasileiro de Pesquisa $e$ Desenvolvimento em Design - P\&D Design 2008. São Paulo: Centro Universitário SENAC, 2008.

PLOWMAN, Tim. Etnography and Critical Design Practices. In: LAUREL, B. Design Research: Methods and Perspective. MITPRESS: Cambridge, 2003.

VALADARES, P. V. R.; COUTINHO, S. G. Um modelo de análise para pesquisas históricas de design gráfico: em busca de características e significados. Anais do P\&D Design 2006. Curitiba: Universidade Federal do Paraná, 2006. 